\title{
Persepsi Petani terhadap Program Upaya Khusus Peningkatan Produksi Padi, Jagung, dan Kedelai (Kasus Teknologi SRI di Subak Lungatad, Desa Peguyangan Kangin, Kecamatan Denpasar Utara, Kota Denpasar)
}

\author{
I GEDE NGURAH SWARNA DWIJA INDRATANAYA, I DEWA PUTU OKA \\ SUARDI, IDA AYU LISTIA DEWI
}

\author{
Program Studi Agribisnis, Fakultas Pertanian, Universitas Udayana \\ Jl. PB. Sudirman Denpasar 80232 Denpasar, Bali \\ Email: indrablast93@gmail.com \\ okasuardi@yahoo.co.id
}

\section{Abstract \\ Perception of Farmers on Special Efforts to Increase Rice, Corn and Soybean Production (The Case of SRI Technology in Subak Lungatad, Peguyangan Kangin Village, Denpasar City)}

The need for food is one of the main aspects for the survival of society. Special Food for food self-sufficiency 2015-2017 is the effort of the Ministry of Agriculture to succeed in self-sufficiency in rice, corn, soybeans in 2017. One of the hopes as the best solution for agriculture in Indonesia in increasing production is through a method of farming patterns with the System of Rice Intensification (SRI). The purpose of this study was to find out the perception of farmers on the Upsus Pajale program, especially SRI technology in Subak Lungatad, Peguyangan Kangin Village, North Denpasar District. The number of samples was 30 farmers. The data were gathered through questionnaires using quantitative and qualitative data types. The data that had been processed were further analyzed using qualitative descriptive analysis method.

Research results show that the farmers' perceptions of SRI technology: (1) innovation was in good category with a score of 3.96, (2) social aspects were in good category with a score of 3.61, (3) economic aspects were in good category with a score of 4.09. And (4) the technical/ environmental aspects were also in the good category with a score of 3.48 .

Based on the results of the research and conclusions obtained, the suggestion that can be made to the government is that they should provide more input on the SRI planting system, both through technical guidance, field practice (making demonstration plots) and mentoring during each planting season, so that the results achieved could be railored to the expectations of all parties. It is also recommended that they should pay more attention to the rice sales system which is currently being sold using a slash system, with the calculation using the area (acre), thus making it difficult for farmers to obtain optimal benefits.

Keywords: perception, farmers, rice, corn, soybeans, SRI technology, subak lungatad 1. Pendahuluan

https://ojs.unud.ac.id/index.php/JAA 


\subsection{Latar Belakang}

Menurut FAO (2014) kebutuhan akan pangan merupakan salah satu yang utama untuk keberlangsungan hidup masyarakat.Produksi padi di Bali tahun 2015 tercatat sebesar 853.710 ton Gabah Kering Giling (GKG) atau mengalami penurunan sebesar 4.234 ton GKG (0,49\%) dibandingkan tahun 2014 (BPS Provinsi Bali, 2016). Berpijak pada permasalahan mendasar tersebut, Kementerian Pertanian menggulirkan program Upaya Khusus (Upsus) Percepatan Pencapaian Swasembada Padi, Jagung, dan Kedelai, atau populer dengan sebutan Upsus Pajale, mulai tahun 2015 (Kementerian Pertanian, 2015a). Salah satu harapan sebagai solusi terbaik bagi pertanian di Indonesia dalam peningkatan hasil produksi yaitu melalui sebuah metode pola tanam pertanian dengan System of Rice Intensification (SRI). SRI merupakan salah satu pendekatan dalam praktek budidaya padi yang menekankan pada manajemen pengelolaan tanah, tanaman dan air melalui pemberdayaan kelompok dan kearifan lokal yang berbasis pada kegiatan ramah lingkungan. Pola tanam padi SRI diharapkan dapat memberikan tambahan produksi sebanyak $1 \mathrm{~s} / \mathrm{d} 2$ ton/Ha, sehingga dapat berkontribusi dalam mensukseskan program surplus beras (Pedoman Teknis Pengembangan SRI TA. 2014).

Kota Denpasar dikelola oleh Subak yang berjumlah 32 subak, salah satunya adalah subak Lungatad di Desa Peguyangan Kangin, Kecamatan Denpasar Utara. Subak Lungatad, terletak di Desa Peguyangan Kangin, Kecamatan Denpasar Utara, memiliki lahan baku seluas 124, 65 hektar, terdiri dari 15 munduk dengan 389 orang petani yang kesemuannya berpengairan setengah teknis, dimana tanaman yang dominan diusahakan adalah tanaman padi dan kedelai dengan pola tanam selama satu tahun (Balai Penyuluhan Pertanian Kecamatan Denpasar Timur, 2014; Hutahuruk et. al., 2016).

Suksesnya suatu program harus diawali dengan adanya pemahaman, dan ketertarikan dari pelaku program. Petani merupakan pelaku pada program Upsus Pajale, oleh karena itu memahami persepsi petani terhadap program tersebut perlu diketahui. Melihat permasalahan tersebut menjadi sangat penting merancang penelitian yang didasarkan atas persepsi masyarakat terhadap program pemerintah dalam pengembangan ekonomi masyarakat dengan judul "Persepsi Petani terhadap Program Upaya Khusus Peningkatan Produksi Padi, Jagung, dan Kedelai (Upsus Pajale) di Subak Lungatad, Desa Peguyangan Kangin, Kota Denpasar”.

\subsection{Rumusan Masalah}

Berdasarkan latar belakang di atas, maka rumusan masalah dalam penelitian ini adalah :

1. Bagaimanapersepsi petani terhadap inovasi sistem tanam SRI,

2. Bagaimanapersepi petani terhadap aspek sosial sistem tanam SRI,

3. Bagaimanapersepsi petani terhadap aspek ekonomi sistem tanam SRI,

4. Bagaimana persepsi petani terhadap aspek teknis/lingkungan sistem tanam SRI,

\subsection{Tujuan}

Tujuan dilakukannya penelitian ini yaitu :

1. Mengetahui bagaimana persepsi petani terhadap inovasi sistem tanam SRI,

2. Mengetahui bagaimana persepi petani terhadap aspek sosial sistem tanam SRI,

3. Mengetahui bagaimana persepsi petani terhadap aspek ekonomi sistem tanam SRI,

https://ojs.unud.ac.id/index.php/JAA 
4. Mengetahui bagaimana persepsi petani terhadap aspek teknis/lingkungan sistem tanam SRI.

\section{Metode Penelitian}

\subsection{Lokasi dan Waktu Penelitian}

Penelitian ini dilakukan di Subak Lungatad Desa Peguyangan Kangin, Kecamatan Denpasar Utara pada bulan Pebruari sampai Maret 2017. Pemilihan lokasi ini dilakukan secara sengaja (purposive),

\subsection{Data Penelitian}

1. Jenis data yang digunakan dalam penelitian ini adalah data kuantitatif dan data kualitatif. Menurut Adi (2004)pengertian data kuantitatif dan kualitatif sebagai berikut:data kuantitatif adalah data yang berbentuk angka atau yang bisa dihitung. Data kuantitatif dalam penelitian ini digunakan untuk mengetahui jumlah anggota subak lungatad, umur, pendidikan, dan juga data lain yang berhubungan dengan penelitian ini. Data kualitatif adalah data yang tidak berbentuk angka, berupa ciriciri, sifat-sifat, keadaan, atau gambaran dari kualitas objek penelitian. Data kualitatif dalam penelitian ini adalah data yang berkaitan dengan persepsi petani terhadap teknologi SRI yaitu Inovasi yang meliputi keuntungan relatif bagi petani, tingkat kesesuaian bagi petani, tingkat kerumitan bagi petani, tingkat kemudahan untuk di coba, tingkat kemudahan di lihat hasilnya. Aspek sosial meliputi kesesuaian adat/kebiasaan yang telah dijalankan oleh subak, terstruktur tidaknya penyuluhan, partisipasi petani dalam organisasi/kelembagaan, keharmonisan hubungan antar petani. Aspek ekonomi meliputi saprodi dan alsintan yang dapat diperoleh dengan harga terjangkau, ketersediaan tenaga kerja, produktivitas usahatani, analisis pasar. Aspek teknis/lingkungan meliputi ketersediaan alsintan ketika diperlukan, sesuai dengan kondisi lahan, ketersediaan air, dan kesesuaian terhadap iklim.

2. Data yang dikumpulkan meliputi data primer dan data sekunder. Data primer merupakan data yang dikumpulkan sendiri oleh perorangan atau suatu organisasi secara langsung dari objek yang diteliti dan untuk kepentingan studi yang bersangkutan. Data primer dalam penelitian ini contohnya adalah jawaban dari pertanyaan yang diajukan langsung dengan memberikan kuisioner kepada responden (data karakteristik petani, inovasi, aspek sosial, aspek ekonomi dan aspek teknis/lingkungan).Data sekunder merupakan data yang diperoleh atau dikumpulkan dan disatukan oleh studi-studi sebelumnya atau yang diterbitkan oleh berbagai instansi lain. Biasanya sumber tidak langsung berupa data dokumentasi dan arsip-arsip resmi. Data sekunder contohnya adalah data Subak Lungatad yang berisi jumlah anggota subak, luas lahan, yang diperoleh dari Dinas Pertanian Tanaman Pangan dan Hortikultura Kota Denpasar, serta data pendukung lain yaitu data produksi padi, jagung, kedelai menurut Kabupaten/Kota di ProvinsiBali pada tahun 2013-2015 yang diperoleh dari Badan Pusat Statistik Provinsi Bali.

\subsection{Teknik Pengumpulan Data, Instrumen Pengumpulan Data, Variabel Penelitian, dan Metode Analisis}

https://ojs.unud.ac.id/index.php/JAA 
Teknik pengumpulan data yang digunakan yaitu teknik wawancara, dan wawancara mendalam. Instrumen pengumpulan data yang dipergunakan dalam peneletian ini yaitu berupa kuesioner yang telah dilakukan melalui uji validitas dan uji realibilitas dengan nilai masing-masing. Variabel pada penelitian ini adalah pengetahuan petani tentang penerapan teknologi SRI. Metode analisis yang dipergunakan adalah analisis deskriptif kualitatif dan kuantitatif.

\subsection{Populasi dan Sampel}

Populasi penelitian ini adalah seluruh petani di Subak Lungatad yang mengikuti program Upsus peningkatan produksi padi, jagung, dan kedelai yaitu sejumlah 195 orang yang terdiri dari 30 orang pemilik sekaligus penggarap lahan dan 165 orang penggarap lahan. Teknik yang digunakan dalam menentukan sampel yaitu Purposive sampling. Jumlah sampel ditetapkan sejumlah 30 orang petani. Alasan pengambilan sampel sebanyak 30 orang responden karena responden tersebut merupakan pemilik dan penggarap yang sudah mengikuti pelatihan metode SRI.

\section{Hasil dan Pembahasan}

\subsection{Karakteristik Responden}

Karakteristik responden dalam penelitian ini meliputi umur, pendidikan, pengalaman yang dimiliki, dan kompetensi teknologi informasi petani.

\subsubsection{Umur}

Kementerian Kesehatan Republik Indonesia membagi kategori umur ke dalam tujuh bagian (Rosdiana, 2013), yaitu ; (1) Masa remaja awal : 12 s.d 16 tahun ; (2) Masa remaja akhir : 17 s.d 25 tahun ; (3) Masa dewasa awal : 26 s.d 35 tahun ; (4) Masa dewasa akhir : 36 s.d 45 tahun ; (5) Masa lansia awal : 46 s.d 55 tahun ; (6) Masa lansia akhir : 56 s.d 65 tahun ; (7) Masa manula : lebih dari 65 tahun. Hasil penelitian menunjukkan bahwa sesuai dengan uraian dari Kementerian Kesehatan Republik Indonesia tentang pembagian kategori umur, menunjukkan bahwa sebagian besar (79,99\%) umur responden masih berada pada usia produktif (16-65 tahun).

\subsubsection{Tingkat pendidikan formal}

Tingkat pendidikan yang memadai membuat petani akan semakin mengerti dan memahami materi-materi yang disampaikan oleh penyuluh serta mempengaruhi kemampuan petani untuk menerima inovasi baru (Thoha, 2004). Hal ini dapat dilihat dari pendidikan dasar Sembilan tahun yang dikenyam responden lebih banyak, yaitu sebanyak 20 orang $(66 \%)$ dari responden yang mengenyam pendidikan SMA yaitu sebanyak 10 orang (33\%). Hal ini mengindikasikan bahwa para petani di Subak Lungatad akan mempunyai pemahaman dan kesulitan dalam menerima teknologi baru yang ditawarkan oleh penyuluh dan akan menimbulkan penolakan dalam penerapan teknologi SRI di Subak Lungatad.

\subsubsection{Pengalaman yang dimiliki}

Pengalaman diartikan sebagai sesuatu yang pernah dialami (dijalankan, dirasakan dan ditanggung) (KBBI, 2005). Pengalaman sangat berkaitan dengan kehidupan sehari-hari dan sangat berharga bagi setiap manusia. Pengalaman juga dapat diberikan kepada siapa saja untuk digunakan dan menjadi pedoman serta pembelajaran manusia.

https://ojs.unud.ac.id/index.php/JAA 
Hasil penelitian ini dapat terlihat bahwa hanya sebagian kecil petani $(6,66 \%)$ yang belum pernah mengikuti pelatihan berupa pembuatan demplot yang dilakukan secara bergiliran di lahan Subak Lungatad, Kota Denpasar. Pelatihan ini memiliki tujuan untuk meningkatkan pengetahuan serta keterampilan petani dalam hal penerapan teknologi SRI pada proses penanaman padi di lahan mereka.

\subsection{Persepsi Petani terhadap teknologi SRI}

Variabel inovasi, skor tertinggi diperoleh oleh indikator keuntungan relatif dengan jumlah skor 129, capaian skor sebesar 4,30 dan termasuk kategori sangat baik, sebaliknya skor terendah diperoleh indikator tingkat kemudahan untuk dicoba dengan jumlah skor sebesar 108, capaian skor sebesar 3,60 dan termasuk kategori baik. Variabel aspek sosial, skor tertinggi diperoleh indikator terstruktur tidaknya penyuluhan dengan jumlah skor sebesar 127, capaian skor sebesar 4,23 dan termasuk kategori sangat baik, sementara skor terendah diperoleh oleh sesuai adat/kebiasaan subak dengan jumlah skor sebesar 90, capaian skor sebesar 3,00 dan termasuk kedalam kategori sedang.

Variabel aspek ekonomi, skor tertinggi diperoleh indikator produktivitas usahatani dengan jumlah skor sebesar 129, capaian skor sebesar 4,30 dan termasuk kategori sangat baik, sementara skor terendah diperoleh indikator saprodi dan alsintan diperoleh dengan harga terjangkau dengan jumlah skor sebesar 116, capaian skor sebesar 3,87 dan termasuk kategori baik. Variabel aspek teknis dan lingkungan, skor tertinggi diperoleh indikator sesuai iklim dengan jumlah skor sebesar 131, capaian skor sebesar 4,37 dan termasuk kategori sangat baik, sementara skor terendah diperoleh indikator alsintan tersedia saat dibutuhkan dengan jumlah skor sebesar 91, capaian skor 3,03 dan termasuk kategori sedang.

\subsubsection{Persepsi petani terhadap inovasi sistem tanam SRI}

Variabel inovasi terhadap sistem tanam SRI yang diukur dalam penelitian ini adalah keuntungan relatif, tingkat kesesuaian, tingkat kerumitan, tingkat kemudahan untuk dicoba serta tingkat kemudahan untuk dilihat hasilnya. Berdasarkan hasil penelitian dapat dilihat nilai tertinggi berada pada indikator keuntungan relatif dengan jumlah skor sebesar 129 yang termasuk kategori sangat baik (dengan rata-rata skor sebesar 4,30). 15 orang petani mempersepsikan sangat baik, sembilan orang mempersepsikan baik dan sisanya enam orang mempersepsikan sedang. Dengan penerapan sistem tanam SRI, petani akan mengalami peningkatan tingkat produktivitas padi sebesar 50\% per hektar. Selain itu dengan jumlah kebutuhan bibit padi yang lebih sedikit dibandingkan dengan sistem konvensional $(5-7 \mathrm{~kg} / \mathrm{ha}$ untuk sistem SRI dibandingkan 30-40 kg/ha untuk sistem konvensional), sistem tanam SRI akan mampu untuk memberikan keuntungan yang lebih besar daripada sistem konvensional yang masih banyak diterapkan oleh petani.

Nilai terendah berada pada variabel tingkat kemudahan untuk dicoba dengan total skor sebesar 108 dengan kategori baik (dengan rata-rata skor sebesar 3,60). Sebanyak tujuh orang petani mempersepsikan sangat baik, 11 orang mempersepsikan baik, lima orang mempersepsikan sedang dan tujuh orang mempersepsikan tidak baik. Hal ini berkaitan dengan masih belum diterapkannya sistem tanam SRI secara menyeluruh sehingga petani masih merasa kesulitan dalam hal penentuan jarak penanaman dan masih memerlukan alat bantu berupa caplak atau rice transplanter yang

https://ojs.unud.ac.id/index.php/JAA 
akan memudahkan petani menanam bibit padi. Masalah ini juga berkaitan dengan mahalnya ongkos buruh tani yang juga belum terlalu mengerti tentang sistem tanam SRI tersebut.

\subsubsection{Persepsi petani terhadap aspek sosial sistem tanam SRI}

Variabel aspek sosial yang diteliti dalam penelitian ini adalah sesuai adat/kebiasaan subak, terstruktur tidaknya penyuluhan, partisipasi dalam kelembagaan/organisasi dan keharmonisan hubungan antar petani. Dari hasil penelitian dapat dilihat bahwa skor terbesar terdapat pada variabel terstruktur tidaknya penyuluhan dengan jumlah skor sebesar 127 dengan kategori sangat baik (dengan rata-rata skor sebesar 4,23). Sebanyak 10 orang petani mempersepsikan sangat baik, 17 orang mempersepsikan baik dan tiga orang mempersepsikan sedang. Penyuluh petani telah memberikan penyuluhan, baik berupa Bimtek (Bimbingan Teknis) ataupun pelatihan pembuatan demplot yang dilakukan secara bergiliran di wilayah Subak Lungatad pada tiap musim tanam. Tujuan dari banyaknya pelatihan yang telah diikuti adalah untuk memperluas pengetahuan dan keterampilan petani agar terbiasa menerapkan sistem teknologi baru dalam proses penanaman padi, dalam kasus ini adalah sistem tanam SRI.

Skor terkecil dari indikator aspek sosial adalah sesuai adat/kebiasaan subak dengan skor sebesar 90 dengan kategori sedang (dengan rata-rata skor sebesar 3,00). Satu orang petani mempersepsikan sangat baik, 13 orang mempersepsikan baik, lima orang mempersepsikan sedang, tujuh orang mempersepsikan tidak baik dan empat orang mempersepsikan sangat tidak baik. Anggota subak masih terbiasa dengan cara konvensional (sistem Tabela) yang sudah dilakukan dalam kurun waktu yang lama sehingga petani menjadi enggan untuk merubah kebiasaan mereka karena sudah terbiasa dan enggan untuk merubah kebiasaan mereka dalam hal menggunakan sistem tanam SRI yang merupakan sebuah inovasi baru yang diharapkan untuk mampu meningkatkan kesejahteraan petani itu sendiri.

\subsubsection{Persepsi petani terhadap aspek ekonomi sistem tanam SRI}

Variabel yang diteliti dalam aspek ekonomi dalam sistem tanam SRI adalah saprodi dan alsintan diperoleh dengan harga terjangkau, tenaga kerja tersedia, produktivitas usahatani, kuantitas hasil dan kualitas hasil. Hasil penelitian dapat dilihat, dapat dijelaskan bahwa skor tertinggi diperoleh variabel produktivitas usahatani dengan skor 129 dengan kategori sangat baik (dengan rata-rata skor sebesar 4,30). Sebanyak 12 orang petani mempersepsikan sangat baik, 15 orang mempersepsikan baik dan sisanya tiga orang mempersepsikan sedang. Hal ini dapat dilihat dari hasil produktivitas menggunakan sistem SRI yang mampu meningkatkan hasil produksi sebesar 50\% jika dilakukan dengan baik dan benar, dimana hal ini akan meningkatkan pendapatan petani yang secara otomatis juga akan meningkatkan kesejahteraan petani.

Skor terkecil terdapat pada variabel saprodi dan alsintan diperoleh dengan harga terjangkau dengan skor sebesar 116 dengan kategori baik (dengan rata-rata skor sebesar 3,87 ). Sebanyak 12 orang mempersepsikan sangat baik, enam orang mempersepsikan baik, delapan orang mempersepsikan sedang dan sisanya tiga orang mempersepsikan kurang baik. Saprodi khususnya, karena belum terbiasanya para petani menerapkan sistem tanam SRI, diperlukan alat bantu berupa caplak yang mempunyai fungsi untuk

https://ojs.unud.ac.id/index.php/JAA 
membuat garis patokan/garis ukur dalam usaha untuk menerapkan sistem SRI. Sementara tidak semua subak mendapatkan bantuan berupa caplak sehingga penerapan sistem SRI belum bisa dilaksanakan secara serempak oleh petani.

\subsubsection{Persepsi petani terhadap aspek teknis/lingkungan sistem tanam SRI}

Variabel yang diteliti dari aspek teknis/lingkungan adalah alsintan tersedia disaat dibutuhkan, sesuai dengan kondisi lahan, ketersediaan air dan sesuai iklim. Dari hasil penelitian dapat dijelaskan bahwa skor tertinggi diperoleh variabel sesuai iklim dengan skor 131 dengan kategori sangat baik (dengan rata-rata skor sebesar 4,37). Sebanyak 16 orang petani mempersepsikan sangat baik, sembilan orang mempersepsikan baik dan sisanya lima orang mempersepsikan sedang. Hal ini dapat dilihat dari salah satu syarat tumbuh tanaman padi menurut Hasanah dan Ina (2007) yaitu tanaman padi sangat cocok untuk tumbuh di iklim yang berhawa panas dan banyak mengandung uap air. Keadaan iklim ini meliputi curah hujan, temperatur, ketinggian tempat, sinar matahari, angin dan musim. Pernyataan tersebut sangat sesuai dengan kondisi iklim di Indonesia dengan iklim tropis yang mempunyai 2 musim (kemarau dan hujan), curah hujan tinggi, serta sinar matahari yang terus bersinar sepanjang tahun.

Sebaliknya, skor terkecil terdapat pada variabel alsintan tersedia saat dibutuhkan dengan skor sebesar 91 dengan kategori sedang (dengan rata-rata skor 3,03). Sebanyak lima orang petani mempersepsikan sangat baik, lima orang juga mempersepsikan baik, sembilan orang mempersepsikan sedang, delapan orang mempersepsikan tidak baik dan sisanya tiga orang mempersepsikan sangat tidak baik. Petani selama ini hanya menggunakan alat berupa sabit beserta gerejag yang digunakan masih secara manual yang dilakukan secara bergotong-royong atau dengan membayar upah buruh untuk ongkos pemanenan. Hal ini dikarenakan teknologi berupa alat pemotong padi otomatis belum mampu digunakan pada lahan di Subak Lungatad karena kondisi geografis lahan sawah yang berpetak-petak $( \pm 10$ are/petak) sehingga akan menyulitkan penggunaan alat pemotong padi yang memiliki ukuran yang cukup besar.

\section{Simpulan dan Saran}

\subsection{Kesimpulan}

Hasil penelitian dapat disimpulkan bahwa persepsi petani terhadap teknologi SRI di Subak Lungatad, Desa Peguyangan Kangin, Kota Denpasar dapat dilihat berdasarkan rincian masing-masing indikator sebagai berikut :

1. Variabel inovasi memperoleh skor sebesar 3,96 dengan kategori baik.

2. Variabel aspek sosial memperoleh skor sebesar 3,61 dengan kategori baik.

3. Variabel aspek ekonomi memperoleh skor sebesar 4,09 dengan kategori baik.

4. Variabel aspek teknis/lingkungan memperoleh skor sebesar 3,48 dengan kategori baik.

\subsection{Saran}

1. Pemerintah melalui Dinas Pertanian dan Balai Penyuluh Pertanian diharapkan untuk lebih banyak memberikan masukan tentang sistem tanam SRI, baik melalui

https://ojs.unud.ac.id/index.php/JAA 
bimbingan teknis (bimtek), praktik lapangan (pembuatan demplot) serta pendampingan pada setiap musim tanam, sehingga hasil yang dicapai dapat sesuai dengan harapan semua pihak.

2. Pemerintah melalui Dinas Pertanian dan Balai Penyuluh Pertanian juga diharapkan dapat merubah kebijakan sistem penjualan padi yang saat ini lebih banyak dijual menggunakan sistem tebasan, dengan perhitungannya menggunakan luas areal (are), sehingga menyebabkan petani sulit mendapatkan keuntungan optimal.

\section{Ucapan Terimakasih}

Penulis menyampaikan terima kasih kepada pengurus Subak Lungatad beserta anggotanya yang telah memberikan data penelitian dan semua pihak yang telah membantu dan memberikan dukungan baik secara moril maupun dalam proses penelitian dan tersusunnya e-jurnal ini.

\section{Daftar pustaka}

Badan Pusat Statistik (BPS). 2016. Produksi Padi, Jagung dan Kedelai (angka tetap tahun 2015). Berita Resmi Statistik Provinsi Bali No. 46/07/51/Th. X, 1 Juli 2016.

Balai Penyuluhan Pertanian Kecamatan Denpasar Timur, 2014. Data Subak Kecamatan Denpasar Timur. Denpasar.

Direktorat Jenderal Prasarana dan Sarana Pertanian. 2014. Pedoman Teknis Pengembangan System Of Rice Intesification. Kementerian Pertanian RI. Jakarta.

FAO. 2014.Save and Grow. A Policy Maker's Guide to the Sustainable Intensification of Smallholder Crop Production. Food and Agriculture Organization. Rome.

Hasanah, Ina. 2007. Bercocok Tanam Padi. Jakarta : Azka Mulia Media.

Hutahuruk, J.K., Lanya, I., Nuarsa, IW. 2016. Sistem Informasi Lahan Subak Berbasis Penginderaan Jauh Dan Sistem Informasi Geografi Di Kota Denpasar. EJurnal Agroekoteknologi Tropika ISSN: 2301-6515 Vol. 5, No. 3, Juli 2016.

KBBI (Kamus Besar Bahasa Indonesia). (2005). Jakarta: PT (Persero) penerbitan dan percetakan.

Kementerian Pertanian RI. 2015a. Modul Pedampingan Mahasiswa Dalam Upaya Khusus Peningkatan Produksi Padi, Jagung, dan Kedelai [UPSUS PAJALE]. Badan Penyuluhan dan Pengembangan Sumberdaya Manusia Pertanian.

Rosdiana, 2013. Faktor-Faktor yang Mempengaruhi Pengetahuan Siswa-Siswi tentang Keluarga Broken Home di Sekolah Menengah Atas Negeri 1 Meureudu Kabupaten Pidie Jaya. \{Jurnal Online\}. Internet. Diunduh pada tanggal 18 Februari 2016.

Thoha, M. 2004. Perilaku Organisasi. Rajawali Press. Jakarta.

https://ojs.unud.ac.id/index.php/JAA 